\title{
In reply: Postoperative pain and study design: the type of surgical procedure matters
}

\author{
Calen Sacevich, MD, MSc • Benjamin Semakuba, MD • William P. McKay, MD • \\ Shefali Thakore, MD $\cdot$ Theogene Twagirumugabe, MD $\cdot$ John Nyiligira, MSc
}

Received: 19 December 2017/ Accepted: 20 December 2017/Published online: 10 January 2018

(C) Canadian Anesthesiologists' Society 2018

Thank you for your interesting observations ${ }^{1}$ regarding our recent report. ${ }^{2}$ It is indeed challenging to do clinical studies in low-income countries (LICs). Regarding our definition of major surgery, the field has been fraught for more than half a century, but a recent study defined it as "... surgeries required general, epidural, or spinal anesthesia, and hospitalization for more than one day".,4 As to the "different pain intensities and temporal patterns" as well as controlling the analgesic regimens of this disparate group of participants, we were interested in looking at a treatment that might be applicable to postoperative pain control as it is actually practiced rather than a transitory ideal regimen that would disappear from practice as soon as the study was over. It is interesting that randomization placed no orthopedic participants in the placebo group. These painful procedures would almost certainly have made the pain score difference greater between the ketamine and placebo groups. We did not record a more detailed presentation of the surgical procedures.

We are uncertain as to what "additional clarification is also needed for the selection of the primary outcome", but there are many possible indicators of pain (hemodynamic, respiratory, skin temperature and conductance, pupillary

C. Sacevich, MD, MSc · W. P. McKay, MD ( $\bowtie)$.

S. Thakore, MD

Department of Anesthesia, University of Saskatchewan,

Saskatoon, SK, Canada

e-mail: bill.mckay@usask.ca

B. Semakuba, MD - T. Twagirumugabe, MD

Department of Anesthesiology, University of Rwanda, Kigali,

Rwanda

J. Nyiligira, MSc

Department of Pharmacy, University Teaching Hospital Kigali, Kigali, Rwanda size, as well as numerical and categorical [written, visual analogue and oral] pain scales), and the numerical verbal response scale (numerical zero to ten) is validated and commonly used for acute postoperative pain, both clinically and experimentally. ${ }^{5}$ The study was exploratory, and we thought it made for a clearer and simpler answer to subcutaneous ketamine efficacy to average the scores over the two days.

Your concern about pain scores being non-normally distributed is dealt with in the report. As stated, we tested for distribution normality with the Shapiro-Wilk test and for equal variance with the Brown-Forsythe test. The pain score data passed those tests, and thus the $t$ test was used.

We thought long and hard about standardizing postoperative analgesic care. The logistics of this would have demanded a much more richly funded study that could include 24-hr shifts of investigator-observers on all surgical wards to ensure compliance. Patient-controlled analgesia was considered, but pumps, drugs, tubing, and staff training were not available to us in this LIC setting. We weighed the benefits of getting on with a more pragmatic and generalizable study against the risks of applying for a very large grant to do a less generalizable study - we chose the former.

Conflicts of interest None declared.

Editorial responsibility This submission was handled by Dr. Philip M. Jones, Associate Editor, Canadian Journal of Anesthesia. 


\section{References}

1. Kendall MC. Postoperative pain and study design: the type of surgical procedure matters. Can J Anesth 2018. https://doi.org/10. 1007/s12630-018-1057-7.

2. Sacevich C, Semakuba B, McKay WP, Thakore S, Twagirumugabe $T$, Nyiligira J. Subcutaneous ketamine for postoperative pain relief in Rwanda: a randomized clinical trial. Can J Anesth 2017. https:// doi.org/10.1007/s12630-017-1009-7.

3. Chang YW, Chou YC, Yeh CC, et al. Outcomes after major surgery in patients with myasthenia gravis: a nationwide matched cohort study. PLoS One 2017; 12: e0180433.
4. Small RG, Witt RE. Major and minor surgery. JAMA 1965; 191: 180-2.

5. Hawker GA, Mian S, Kendzerska T, French M. Measures of adult pain: Visual Analog Scale for Pain (VAS Pain), Numeric Rating Scale for Pain (NRS Pain), McGill Pain Questionnaire (MPQ), Short-Form McGill Pain Questionnaire (SF-MPQ), Chronic Pain Grade Scale (CPGS), Short Form-36 Bodily Pain Scale (SF-36 BPS), and Measure of Intermittent and Constant Osteoarthritis Pain (ICOAP). Arthritis Care Res (Hoboken) 2011; 63(Suppl 11): S240-52. 